\title{
CD24 GENE POLYMORPHISMS IN EGYPTIAN PATIENTS WITH COLORECTAL CANCER
}

\author{
Eman Saber Elhennawy ${ }^{1} \square\left(D\right.$, Abeer Mesbah Abd-El Hamid ${ }^{2} \square$, Tharwat Saad Kandil ${ }^{3} \square$, \\ Mohammed Mohammed El-Sayed El-Arman $4 \square$, Rasha Elzehery $5 \square$ \\ 1,2,4,5 Department of Clinical Pathology, Faculty of Medicine, Mansoura University, Mansoura, Egypt. \\ ${ }^{3}$ Department of Gastroenterology, Faculty of Medicine, Mansoura University, Mansoura, Egypt.
}

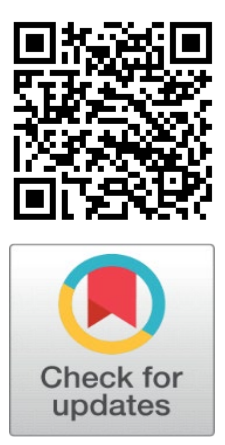

Received 16 September 2021

Accepted 16 October2021

Published 31 October2021

CorrespondingAuthor

Rasha Elzehery,

rasharizk76@yahoo.com

DOI

10.29121/granthaalayah.v9.i10.2021 4344

Funding: This research received no specific grant from any funding agency in the public, commercial, or not-for-profit sectors.

Copyright: (C) 2021 The Author(s). This is an open access article distributed under the terms of the Creative Commons Attribution License, which permits unrestricted use, distribution, and reproduction in any medium, provided the original author and source are credited.

\section{ABSTRACT}

Introduction: Early detection of colorectal cancer (CRC) is the key to reduce its related morbidity and mortality.

Methods: One hundred CRC patients were included in this study, they were admitted at Mansoura Gastroenterology Center, Mansoura University and diagnosis was confirmed by pathology.100 apparently healthy individuals were served as the control group.CD24 (P170 C/T) and CD24 (P-534 A/C) single nucleotide polymorphisms (SNPs) were analyzed using polymerase chain reaction-restriction fragment length polymorphism (PCR/RFLP).

Results: Regarding CD24 P170 C/T SNP, no statistically significant association was found between genotypes, alleles and risk of CRC. While, P-534 A/C; AC, CC, AC+CC genotypes and $C$ allele showed significantly higher frequency in cases when compared to controls. CC and TC haplotypes were significantly associated with risk of CRC when compared to control group. Multivariate logistic regression analysis revealed that higher CEA and P$534 \mathrm{~A} / \mathrm{C}(\mathrm{AC}+\mathrm{CC})$ were considered as independent predictors of higher CRC stages. Conclusion: The current study observed an association between CD24 P-543 A/C SNP and the risk of developing CRC in Egyptian subjects.

Keywords: CD24, Colorectal Cancer, Single Nucleotide Polymorphism, Carcinogenesis

\section{INTRODUCTION}

Colorectal cancer (CRC) is the third most common cancer in the world and is characterized by its high lethality and morbidity Siegel et al. (2020). It is one of the major leading causes of death in both males and females as it was responsible for 861,000 deaths worldwide in 2018 Bray et al. (2018).

It is a very heterogeneous disease that is caused by the interaction of genetic and environmental factors. It develops through a gradual accumulation of genetic and epigenetic changes leading to the transformation of normal colonic mucosa into an invasive cancer Binefa et al. (2014).

Over $70 \%$ of CRC cases are sporadic and related to lifestyle Giovannucci (2002). The known risk factors for CRC include; a diet low in fruit and vegetables, excessive intake of red meat and saturated fat, alcohol intake, a sedentary lifestyle, smoking and obesity Gonzalez and Riboli (2010).

Early detection of CRC is the key to reduce its related mortality Ladabaum et al. (2020). So, a number of screening modalities are recommended for CRC detection. Colonoscopy and fecal occult blood testing (FOBT) are most often recommended. While colonoscopy is considered the "golden standard" for CRC 
screening, it is expensive and invasive and carries a number of risks including bleeding and perforation. FOBT, although noninvasive, is limited by low sensitivity and poor compliance since its annual testing are required Kraus et al. (2015).

CD24 is implicated in the pathogenesis of cancer and inflammatory diseases due to its ability to bind for P-selectin, allowing tumor cell dissemination and lymphocyte recruitment to inflamed tissues Kristiansen et al. (2014).

CD24 is associated with tumor growth, invasion, metastasis, recurrence and treatment response in various cancers, including breast, prostate, colorectal, hepatocellular and gastric cancer Jia et al. (2016).

Additionally, it is a potential marker of cancer stem cells (CSCs), which have capabilities for tumorigenesis, self-renewal and producing differentiated progeny Ke et al. (2012). CD24 expression has been reported to be commonly upregulated in CRC and has been shown to be a marker of poor prognosis suggesting a significant role in the oncogenic pathway involved in CRC carcinogenesis Yeo et al. (2016).

Genetic variations, as single-nucleotide polymor $\neg$ phisms (SNPs), could affect the transcriptional efficiency of genes, as well as structure (and so, function) of the protein products Kwon et al. (2011).

Human CD24 gene is located on chromosome 6q21 Fang et al. (2010). Notably, two functional polymorphisms were identified at CD24 gene, P170 C/T and P1527 TG/deletion Li et al. (2009) and a new functional CGC haplotype (P-534C/-492G/442C) in the promoter region Wang et al. (2012).

Polymorphisms of CD24 have been related to prognosis in several cancers. In breast cancer, CD24 expression was associated with adverse prognosis Horiguchi et al. (2010) and CD24 P170 polymorphism could predict response to chemotherapy Buck et al. (2013). In esophageal cancer, P170 of CD24 was involved in regional lymph node metastasis Sadot et al. (2014).

The inconsistent results of these studies make studying the relation between CD24 gene polymorphisms and susceptibility to CRC in Egyptian patients important in this work.

The aim of this present study was to evaluate the association between two CD24 gene polymorphisms (P170 C/T and P-534 A/C) and CRC in Egyptian patients.

\section{SUBJECT AND METHOD \\ 2.1. SUBJECTS}

This study was conducted on 100 CRC patients (52 males and 48 females with their ages ranged from 22 to 71 years) admitted at Mansoura Gastroenterology Center, Mansoura University and diagnosis was confirmed by pathology.100 apparently healthy individuals (53 males and 47 females with their agesranged from 28 to 72 years) were served as the control group, they were selected randomly and matched to cases for age and sex.

The local ethics committee gave their prior approval to the study (code number: MD/17.08.32). The work has been carried out in accordance with the Code of Ethics of the World Medical Association (Declaration of Helsinki) for experiments in humans. All patients and healthy controls signed informed consent forms. Detailed history, clinical assessment including complete examination, TNM staging, tumor site, and the results of histopathological examination were done.

AJCC staging 8th edition (2017) was utilized in the staging of CRC patients and classifying them into, early stage (stage I + II) and late stage (stage III + IV) Amin et al. (2017). Cases with history of other malignancies or autoimmune diseases were excluded. 


\subsection{SAMPLING}

A five $\mathrm{mL}$ peripheral whole-blood specimen was collected from all cases and controls and divided into; three ml were delivered into a plain sterile vacutainer tube, centrifuged at $3000 \mathrm{rpm}$ and the separated serum was used for assay of routine chemical tests, CEA and CA 19.9. Two ml were delivered into a sterile EDTA vacutainer tube for $\mathrm{CBC}$ and $\mathrm{CD} 24$ genotyping. EDTA samples were stored at $-20^{\circ} \mathrm{C}$ for DNA extraction.

Routine chemical investigations: including liver function tests, serum creatinine and random blood sugar were done on HITACHI 902 (automatic analyzer, Japan, serial no.1928013). Complete Blood Count (CBC) was done using Sysmex Xp300.Tumor markers: including serum CEA and CA 19-9 were assayed by automated device ARCHITECT PLUS (Singaphore, serial no. Isr50405).

\subsection{GENOTYPING}

Thermo Scientific Gene JET whole Blood Genomic DNA Purification Mini Kit (cat no k0781, Lithuania, USA) was used for the extraction of genomic DNA from peripheral blood leukocytes.

Enzymatic amplification was performed using thermal cycler ( $\mathrm{T}$ personal thermo cycler, Biometra, analytical Jena Company). A pair of primers (Bio Basic Canada Inc.); forward (F) and reverse (R), for each SNP was used. Lyophilized primers were reconstituted by addition of appropriate volume of nuclease free water. Sequence of primers used for PCR reactions for detection of CD24 SNPs was according to Kraus et al. (2015) as regard P170 C/T and Jia et al. (2016) as regard $\mathrm{P}-534 \mathrm{~A} / \mathrm{C}$.

Primers for P170 C/T SNP: F: 5'-TTGTTGCCACTTGGCATTTTTGAGGC-3 and R: 5'-GGATTGGGTTTAGAAGATGGGGAAA-3

Primers for P-534 C/A SNP: F: 5'-AGAGATAACCCTGCCCGAG-3' and R: 5'CCAAGTTTCCTTTGTTTCCC-3'

For each reaction the following were added to a $0.2 \mathrm{ml}$ eppendorf: $12.5 \mathrm{uLblue}$ PCR master mix, forward primer $(0.1 \mathrm{uL})$, reverse primer $(0.1 \mathrm{uL})$, extractedDNA (2 $\mathrm{uL})$ and water nuclease-free $(10.3 \mathrm{uL})$ forming a total of $25 \mathrm{uL}$.

For CD24 P $170 \mathrm{C} / \mathrm{T}$ genotyping, the reaction mixture had initial denaturation at $95^{\circ} \mathrm{C}$ for $3 \mathrm{~min}$; followed by 35 cycles of denaturation at $95^{\circ} \mathrm{C}$ for $30 \mathrm{sec}$; annealing at $64{ }^{\circ} \mathrm{C}$ for $30 \mathrm{sec}$; extension $30 \mathrm{sec}$ at $72{ }^{\circ} \mathrm{C}$ and the final extension at $72{ }^{\circ} \mathrm{C}$ for 5 $\min$.

For CD24 P-534 A/C genotyping, the reaction mixture had initial denaturation at $95^{\circ} \mathrm{C}$ for $3 \mathrm{~min}$; followed by 35 cycles of denaturation at $94^{\circ} \mathrm{C}$ for 30 sec; annealing at $55^{\circ} \mathrm{C}$ for $30 \mathrm{sec}$; extension $30 \mathrm{sec}$ at $72{ }^{\circ} \mathrm{C}$ and the final extension at $72^{\circ} \mathrm{C}$ for $5 \mathrm{~min}$.

For CD24 P $170 \mathrm{C} / \mathrm{T}$ genotyping, the PCR products were digested with BstXI (New England Biolabs, Inc., cat no R0113S) for about 5 min at 37으. The PCR products (454bp) with T allele were divided into two fragments (325bp and 129bp) while the PCR products with $\mathrm{C}$ allele remained undigested, so yield one fragment at (454bp), Figure 1.

To detect CD24 P-534 A/C genotypes, BsrFI- v2(New England Biolabs, Inc., cat no R0682S) was used for 1 hour at $37^{\circ} \mathrm{C}$. The PCR products (209bp) with A allele remained undigested, so yield one fragment at (209bp), while the PCR products with $\mathrm{C}$ allele were divided into two fragments (126bp and 83bp), Figure 2 


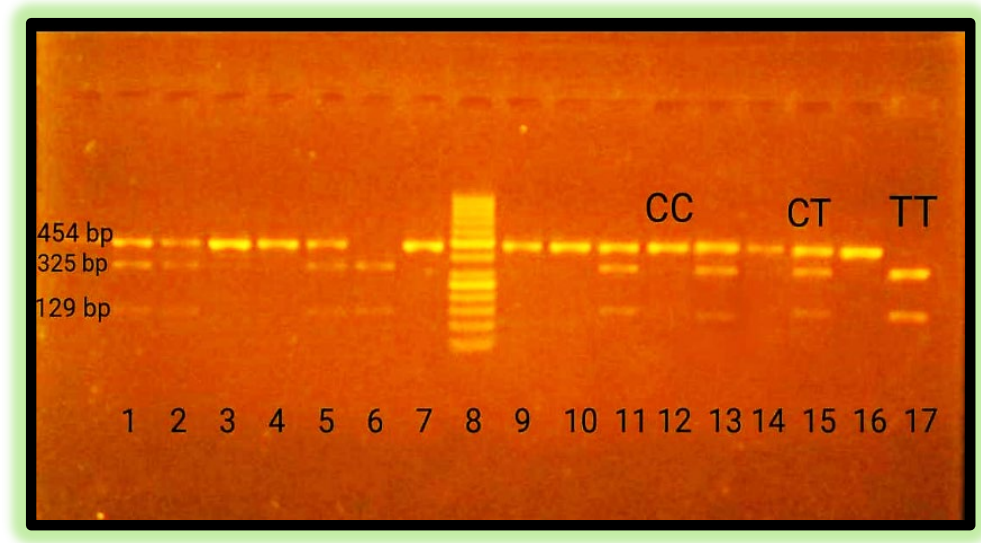

Figure 1 Agarose gel electrophoresis of PCR products digested wit BstXI restriction enzyme

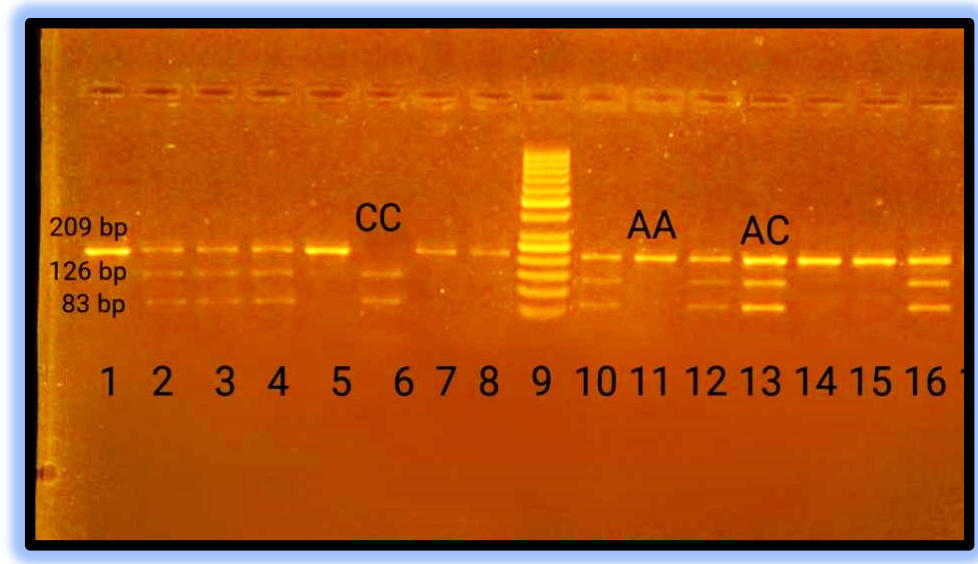

Figure 2 Agarose gel electrophoresis of PCR products digested with BsrFI- v2 restriction enzyme

AA homozygous wild type was identified as a single band at $209 \mathrm{bp}$, while two bands at $126 \mathrm{bp}$ and83 bp indicated CC mutant homozygous individuals, and AC heterozygote appeared as three bands at $209 \mathrm{bp}, 126 \mathrm{bp}$ and $83 \mathrm{bp}$.

The statistical analysis of studied data was done by using IBM SPSS (Statistical package for Social Science) program, Version 20.0.

\section{RESULTS}

Abdominal pain was the most common presenting symptom in cancer colon patients $(72.7 \%)$ while bleeding per rectum (53.3\%) was the commonest symptom in cancer rectum patients.55\% of the tumors resided in the colon, $45 \%$ in the 
rectum, 59\% had early, $41 \%$ had advanced stages; $31 \%$ had mucinous adenocarcinoma and $69 \%$ had adenocarcinoma.

CEA and CA19-9 were significantly higher and hemoglobin concentration was significantly lower in cases when compared to control group. Otherwise, no significant differences were found in clinical chemistry data between cases and control group (table 1).

This sample of individuals was selected randomly from population in Dakahleya Governorate in Egypt. Applying Hardy Weinberg equation, revealed that $\mathrm{P} 170 \mathrm{C} / \mathrm{T}$ and P-534 A/C genotypes in control as well as in patient groups were in HW equilibrium ( $p=0.105, p=0.502$ respectively).

Regarding CD24 P170 C/T SNP, no statistically significant association was found between genotypes, alleles and risk of CRC. Regarding CD24 P-534 A/C SNP; $\mathrm{AC}, \mathrm{CC}, \mathrm{AC}+\mathrm{CC}$ genotypes and $\mathrm{C}$ allele showed significantly higher frequency in cases when compared to control group ( $p=0.043,0.002,0.007,0.001$ Respectively). AC, CC genotypes, dominant model $(\mathrm{AC}+\mathrm{CC})$ and $\mathrm{C}$ allele were associated with risk to develop CRC (OR=1.459, 3.319, 1.627, 1.548 respectively) (table2).

CD24P170 C/T - P-534 A/C haplotypes were calculated; CA showed the highest prevalence, while TC showed the lowest prevalence in CRC and control groups.CC and TC haplotypes were significantly associated with risk of developing CRC when compared to control group. No statistically significant differences were found in age, gender, smoking, FH, premalignant lesions and laboratory data between CD24 P170 $\mathrm{C} / \mathrm{T}$ genotypes in all studied CRC cases (table 3 ). No significant differences were found in clinical data, pathological data and 2-years OS between CD24 P170 C/T genotypes in all studied CRC cases.

No significant differences were found in demographic data, CRC risk factors and laboratory data between CD24P-534 A/C genotypes in all studied CRC cases (table 3). No significant differences were found in clinical data between CD24 P-534 A/C genotypes in all studied CRC cases.CC and AC genotypes as well as dominant model $(\mathrm{AC}+\mathrm{CC})$ were significantly associated with advanced stage, while AC genotype and dominant model $(\mathrm{AC}+\mathrm{CC})$ were significantly associated with $\mathrm{LN}$ metastasis. Otherwise, no significant differences were found in tumor criteria between CD24 P$534 \mathrm{~A} / \mathrm{C}$ genotypes in all studied CRC patients. No significant differences were found regarding 2-years OS between P-534 A/C genotypes in all studied CRC cases.

Regression analysis was conducted for prediction of CRC, using age, gender, HGB level, CEA, CA19-9, CD24 genotypes as covariates. Higher CEA, higher CA19-9, P-534 A/C dominant model (AC+CC) and lower HGB levels were significantly associated with risk of developing CRC in univariate analysis. However, taking significant covariates into multivariate analysis revealed that higher CEA and lower HGB levels were significantly associated with risk of CRC occurrence (table 4).

Cox regression analysis was conducted for prediction of OS in CRC cases using age, gender, HGB, CEA, CA19-9, CD24 genotypes as risk factors. None was significantly associated with prediction of shorter OS.

\section{DISCUSSION}

CRC is the third most common cancer in the world and it is characterized by its high lethality and morbidity Siegel et al. (2020). Early detection of CRC is the key to reduce its related mortality Ladabaum et al. (2020). Colon CSCs (CCSCs) are multipotent neoplastic cells that have the ability to differentiate and initiate the carcinogenesis process Ribeiro et al. (2016). Due to increased viability of CCSCs, 
they are responsible for both tumor growth and tumor recurrence Spelt et al. (2018).

Given the potentialimportance of CD24 oncogenic function in CRC, this present study was aimed to evaluate the association between two CD24 gene polymorphisms (P170 C/T and P-534 A/C) and CRC in Egyptian patients.

The mean age of CRC patients in this study was $50.8 \pm 11.2$ years. Youssef et al. (2017) and Gado et al. (2014) found similar results as they reported that the mean age of CRC Egyptian patients ranged from 50 to 62 years. However, Parkin et al. (2005) found that the average age of CRC occurrence was about 65 years in western populations. In Egypt, Abou-Zeid et al. (2002) reported that more than one third of CRC tumors affect young population and Soliman et al. (2001) observed that $44 \%$ of CRC patients were under the age of 40 years old.

Gender distribution among studied patients showed slightly increased incidence of CRC in males (52\%) more than females (48\%). This result was coincided with Jover et al. (2006), Aljebreen (2007), Youssef et al. (2013) and Fan et al. (2013) who observed increased the incidence of CRC in males than in females. This could be explained by increased risk factors as smoking and alcohol consumption among males more than females Song et al. (2015).

The current study showed that, abdominal pain was the most common presenting symptom of cancer colon patients $(72.7 \%)$ while bleeding per rectum $(53.3 \%)$ was the commonest symptom in cancer rectum patients. These findings were in accordance with Corner et al. (2010), McFarlane et al. (2004) and Aljebreen (2007) who reported similar results.

When univariate analysis was done, higher CA19-9 and CEA levels were associated with risk of advanced CRC stages. However, in multivariate analysis, higher CEA only was considered as independent predictors of higher CRC stages. These findings were consistent with Nadeem et al. (2019), Tomašević et al. (2016), Stojkovic Lalosevic et al. (2017) and Wang et al. (2015) studies which showed that CEA levels were significantly elevated in late stages and distant metastases of CRC.

While, Polat et al. (2014) reported that serum CA 19-9 level didn't differ by CRC stage, but serum CEA level was significantly elevated in advanced cases, so CEA could be a predictor of advanced stages of CRC. On the other hand, Kim et al. (2017) stated that both elevated serum CEA and CA 19-9 levels were associated with the presence of CRC and were correlated with its severity

In this study, CD24P170 C/T and P-534 A/CSNPs were tested for HW equation and it revealed that $\mathrm{P} 170 \mathrm{C} / \mathrm{T}$ and $\mathrm{P}-534 \mathrm{~A} / \mathrm{C}$ genotypes in controls as well as in cases were in HW equilibrium ( $\mathrm{P}>0.001$ for each).

$\mathrm{CD} 24 \mathrm{P} 170 \mathrm{C} / \mathrm{T}$ is located in the coding region of exon2 of CD24 gene and its Cto- $\mathrm{T}$ transition leads to an alanine to valine substitution at codon 57 near the GPI anchorage site of the mature CD24 protein Jia et al. (2016).

Regarding CD24 P170 C/T, no significant association was found between genotypes or alleles and risk of CRC. These results agreed with those of Kraus et al. (2010), Kristiansen et al. (2014) who found no correlation between CD24 P170 C/T and the prevalence of either adenomas or CRC in comparison with control healthy groups.

However, Kraus et al. (2015) found thatCD24 expression in peripheral blood lymphocytes (PBLs) can serve as a potential promising screening tool to select which healthy subjects are at risk of having CR neoplasia and need to undergo screening colonoscopy.

Kraus et al. (2010) reported that there were no significant correlations between the expression of CD24 protein and CD24 P170 C/T SNP. However, 
preliminary data showed that the $\mathrm{P} 170 \mathrm{C} / \mathrm{T}$ variant may increase susceptibility to CR adenomas $(\mathrm{p}=0.048)$.

In other GI cancers, Jia et al. (2016) did not observe any influence of CD24 P170 $\mathrm{C} / \mathrm{T}$ on GC occurrence or observe any differences of CD24 expression among P170genotypes. Sadot et al. (2014) did not find any significant difference between esophageal cancer patients and controls in CD24 P170 C/T SNP.

On the other hand, many studies have reported that CD24 P170 C/T is correlated with risk of other cancers, as Sheng and Shui (2011) showed thatP170T/T genotype correlated with a 2.96-fold increase of HCC. Also, Zhang et al. (2017) suggested that P170T/T genotype is a genetic risk factor for prostate cancer onset.

In a meta-analysis included five individual case-control to investigate the role of CD24 gene polymorphism in human cancers, Yan et al. (2014) showed that no significant association was identified between P170 C/T and breast cancer or HCC as regard its alleles and genotypes.

As IBD is an important risk factor for CRC, Diaz-Gallo et al. (2011) revealed that there were no statistically significant differences in the allelic frequencies of CD24 P170 C/T SNP between both CD or UC patients and controls. However, Lisiansky et al. (2014) found that the P170T allele was associated with increased IBD risk $(\mathrm{p}=0.001)$, UC ( $\mathrm{p}=0.001)$ and $\mathrm{CD}(\mathrm{p}=0.008)$.

In a meta-analysis, Huang et al. (2015) revealed that the CD24 C170T polymorphism was associated with an increased risk of UC $(\mathrm{P}=0.009)$, but not CD.

The CD24 P-534 SNP, which is located in the promoter region, may influence transcriptional activity of CD24 gene and thus could affect the level of CD24 protein expression and may be involved in cancer aggressiveness Wang et al. (2012).

In the present study, $\mathrm{AC}, \mathrm{CC}, \mathrm{AC}+\mathrm{CC}$ genotypes and $\mathrm{C}$ allele of CD24 P-534 A/C SNP showed significantly high risk to develop CRC $(p=0.043,0.002,0.007,0.001$ respectively).

To our knowledge, the available data about the association between CD24 P534 A/C SNP and CRC were limited. However, there were few studies that demonstrate the oncogenic role of CD24P-534 A/CSNP in the onset and progression of other human cancers Jia et al. (2016), Zhang et al. (2017).

Zhang et al. (2017) found that patients with CD24 P-534 CC genotype had a 1.47-fold increased risk of prostate cancer compared to those with the P-534 AA genotype, suggesting that the $\mathrm{P}-534 \mathrm{C}$ allele is a genetic risk factor for prostate cancer.

However, Jia et al. (2016) found no correlation between P-534 A/C and gastric cancer and also did not observe any association of CD24 expression and P-534 A/C genotypes.

The combination of multiple alleles on one chromosome is defined as a haplotype. The analysis of haplotypes could provide more information than singlelocus analysis. In this study, four possible haplotypes (CA, CC, TA and TC) were detected. But only CC and TC haplotypes were significantly associated with risk of CRC when compared to control group.

Wang et al. (2012) showed that a haplotype that contained the $\mathrm{C}$ allele of CD24 P-534 SNP was involved in a higher transcriptional activity and increased expression of CD24 in peripheral blood lymphocytes of multiple sclerosis patients. Zhang et al. (2017) reported that tumors with a combination of P170T/T and P534C/C genotypes were associated with a high mRNA level of CD24 in prostate cancer patients. 
In contrary to these results, Jia et al. (2016) failed to find any association between haplotypes containing P170 C/T or P-534 C/A alleles and gastric cancer.

As regard the pathological data, CD24 P170 C/T SNP showed no statistical significant difference in CRC patients, but CC genotype of CD24 P-534 A/C SNP as well as dominant model $(\mathrm{AC}+\mathrm{CC})$ were significantly associated with advanced stage, and LN metastasis in CRC studied cases.

In accordance with our results, Gerger et al. (2011) found no significant association between CD24 P170 C/T SNP and tumor recurrence suggesting no role of CD24 P170 C/T SNP in CRC prognosis.

However, Sadot et al. (2014) reported that P170 TT genotype was involved in regional lymph node metastasis in esophageal cancer patients and Zhang et al. (2017) found that P170 TT genotype was associated with advanced prostate cancer stages, but they failed to find any association between P-534 A/C and late stages.

In this study, Cox regression analysis was conducted for prediction of overall survival (OS) in CRC cases using age, gender, HGB, CEA, CA19-9, CD24 genotypes as risk factors. None was associated with prediction of shorter OS. Controversy to this finding, Jia et al. (2016) demonstrated that P-534 A/A and P170 T/T genotypes carriers tended to have shorter survival than non-carriers in gastric cancer patients.

\section{CONCLUSION}

The current study did not observe any differencesbetweenCD24 P170 C/T SNP and CRC risk, while CD24 P-543 C allele was associated with CRC as regard onset and progression. This disparity in results may be due to difference in ethnic groups, sample size or different environmental factors. Therefore, further related studies of a larger sample size and associated estimation of CD24 protein expression should be carried out to verify this association.

\section{ETHICAL APPROVAL}

This study was ethically approved by Mansoura University Ethics Committee at the faculty of Medicine (code number: MD/17.08.32).

\section{INFORMED CONSENT}

An informed consent was obtained from each participant.

\section{DECLARATION OF COMPETING INTEREST}

No potential conflict of interest was reported by the authors.

\section{ACKNOWLEDGMENTS}

This work was granted by the authors themselves. This research received no specific grant from any funding agency in the public, commercial or not-for-profit sectors.

\section{REFERENCES}

Abou-Zeid A A, Khafagy W, Marzouk D M, et al. (2002) Colorectal cancer in Egypt. Diseases of the colon and rectum. 45: 1255-1260. Retrieved from https://doi.org/10.1007/s10350-004-6401-z 
Aljebreen A M. (2007) Clinico-pathological patterns of colorectal cancer in Saudi Arabia: younger with an advanced stage presentation. Saudi journal of gastroenterology: official journal of the Saudi Gastroenterology Association; 13: 84-87. Retrieved from https://doi.org/10.4103/1319-3767.32183

Amin M B, Greene F L, Edge S B, et al. (2017) The Eighth Edition AJCC Cancer Staging Manual: Continuing to build a bridge from a population-based to a more "personalized" approach to cancer staging. CA Cancer J Clin. 67: 93-99. Retrieved from https://doi.org/10.3322/caac.21388

Binefa G, Rodríguez-Moranta F, Teule A et al. (2014) Colorectal cancer: from prevention to personalized medicine. World journal of gastroenterology. 20: 6786-6808. Retrieved from https://doi.org/10.3748/wjg.v20.i22.6786

Bray F, Ferlay J, Soerjomataram I, et al. (2018) Global cancer statistics: GLOBOCAN estimates of incidence and mortality worldwide for 36 cancers in 185 countries. CA Cancer J Clin. 2018; 68: 394-424. Retrieved from https://doi.org/10.3322/caac.21492

Buck K, Hug S, Seibold P, et al. (2013) CD24 polymorphisms in breast cancer: impact on prognosis and risk. Breast cancer research and treatment. 137: 927-937. Retrieved from https://doi.org/10.1007/s10549-012-2325-9

Corner C, Bryant L, Chapman C, et al. (2010) High-dose-rate afterloading intraluminal brachytherapy for advanced inoperable rectal carcinoma. Brachytherapy; 9: 66-70. Retrieved from https://doi.org/10.1016/j.brachy.2009.07.004

Diaz-Gallo L M, Medrano L M, Gómez-García M, et al. (2011) Analysis of the influence of two CD24 genetic variants in Crohn's disease and ulcerative colitis. Hum Immunol. 72: 969-972. Retrieved from https://doi.org/10.1016/j.humimm.2011.05.028

Fan Y, Zhang X, Yang Z-H, et al. (2013) The polymorphisms of osteopontin gene and plasma osteopontin protein levels with susceptibility to colorectal carcinoma. DNA and cell biology; 32: 594-600. Retrieved from https://doi.org/10.1089/dna.2013.2090

Fang X, Zheng P, Tang J et al. (2010) CD24: from A to Z. Cellular \& Molecular Immunology; 7: 100-103. Retrieved from https://doi.org/10.1038/cmi.2009.119

Gado A, Ebeid B, Abdelmohsen A et al. (2014) Colorectal cancer in Egypt is commoner in young people: Is this cause for alarm? Alexandria Journal of Medicine; 50: 197-201. Retrieved from https://doi.org/10.1016/j.ajme.2013.03.003

Gerger A, Zhang W, Yang D, et al. (2011) Common Cancer Stem Cell Gene Variants Predict Colon Cancer Recurrence. Clinical cancer research : an official journal of the American Association for Cancer Research; 17: 6934-6943. Retrieved from https://doi.org/10.1158/1078-0432.CCR-11-1180

Giovannucci E. (2002) Modifiable risk factors for colon cancer. Gastroenterology clinics of North America; 31: 925-943. Retrieved from https://doi.org/10.1016/S0889-8553(02)00057-2

Gonzalez C A and Riboli E. (2010) Diet and cancer prevention: Contributions from the European Prospective Investigation into Cancer and Nutrition (EPIC) study. European journal of cancer; 46: 2555-2562. Retrieved from https://doi.org/10.1016/j.ejca.2010.07.025

Horiguchi K, Toi M, Horiguchi S-I, et al. (2010) Predictive value of CD24 and CD44 for neoadjuvant chemotherapy response and prognosis in primary breast 
cancer patients. Journal of medical and dental sciences; 57: 165-175. Retrieved from https://doi.org/10.1016/j.ejcsup.2011.02.010

Huang X L, Xu D H, Wang G P, et al. (2015) Associations between CD24 gene polymorphisms and inflammatory bowel disease: A meta-analysis. World J Gastroenterol; 21: 6052-6059. Retrieved from https://doi.org/10.3748/wjg.v21.i19.6052

Jia Z F, Wang L Z, Cao X Y, et al. (2016) CD24 genetic variants contribute to overall survival in patients with gastric cancer. World J Gastroenterol. 22: 23732382. Retrieved from https://doi.org/10.3748/wjg.v22.i7.2373

Jover R, Zapater P, Castells A, et al. (2006) Mismatch repair status in the prediction of benefit from adjuvant fluorouracil chemotherapy in colorectal cancer. Gut; 55: 848-855. Retrieved from https://doi.org/10.1136/gut.2005.073015

Ke J, Wu X, Wu X, et al. (2012) Subpopulations of CD24+ cells in colon cancer cell lines possess stem cell characteristics. Neoplasma; 59: 282-288. Retrieved from https://doi.org/10.4149/neo_2012_036

Kim N H, Lee M Y, Park J H, et al. (2017) Serum CEA and CA 19-9 Levels are Associated with the Presence and Severity of Colorectal Neoplasia. Yonsei Med J; 58: 918-924. Retrieved from https://doi.org/10.3349/ymj.2017.58.5.918

Kraus S R, Naumov I, Kazanov D, et al. (2010) Abstract 2902: A simple blood test, evaluating the level of CD24 protein, can detect subjects with colorectal adenomas and adenocarcinomas. Cancer Research; 70: Retrieved from https://doi.org/10.1158/1538-7445.AM10-2902

Kraus S, Shapira S, Kazanov D, et al. (2015) Predictive Levels of CD24 in Peripheral Blood Leukocytes for the Early Detection of Colorectal Adenomas and Adenocarcinomas. Dis Markers; 916098. Retrieved from https://doi.org/10.1155/2015/916098

Kristiansen G, Sammar M and Altevogt P. (2014) Tumour biological aspects of CD24, a mucin-like adhesion molecule. J Mol Histol; 35: 255-262. Retrieved from https://doi.org/10.1023/B:HIJ0.0000032357.16261.c5

Kwon E M, Salinas C A, Kolb S, et al. (2011) Genetic polymorphisms in inflammation pathway genes and prostate cancer risk. Cancer epidemiology, biomarkers \& prevention: a publication of the American Association for Cancer Research, cosponsored by the American Society of Preventive Oncology; 20: 923-933. Retrieved from https://doi.org/10.1158/1055-9965.EPI-10-0994

Ladabaum U, Dominitz J A, Kahi C et al. (2020) Strategies for Colorectal Cancer Screening. Gastroenterology; 158: 418-432. Retrieved from https://doi.org/10.1053/j.gastro.2019.06.043

Li D, Zheng L, Jin L, et al. (2009) CD24 polymorphisms affect risk and progression of chronic hepatitis B virus infection. Hepatology; 50: 735-742. Retrieved from https://doi.org/10.1002/hep.23047

Lisiansky V, Kraus S, Naumov I, et al. (2014) Role of CD24 polymorphisms in the susceptibility to inflammatory bowel disease. The International journal of biological markers; 29: e62-e68. Retrieved from https://doi.org/10.5301/jbm.5000072

McFarlane M E C, Rhoden A, Fletcher P R et al. (2004) Cancer of the colon and rectum in a Jamaican population: diagnostic implications of the changing frequency 
and subsite distribution. The West Indian medical journal; 53: 170-173. Retrieved from https://europepmc.org/article/med/15352746

Nadeem M, Karunanand B, Bhat S et al. (2019) CEA levels in colorectal carcinoma, correlation with the tumor staging, and CEA as independent predictor of prognosis of colorectal cancers; 3: 210-213.

Parkin D M, Bray F, Ferlay J et al. (2005) Global cancer statistics, 2002. CA: a cancer journal for clinicians; 55: 74-108. Retrieved from https://doi.org/10.3322/canjclin.55.2.74

Polat E, Duman U, Duman M, et al. (2014) Diagnostic value of preoperative serum carcinoembryonic antigen and carbohydrate antigen 19-9 in colorectal cancer. Current oncology; 21: e1-e7. Retrieved from https://doi.org/10.3747/co.21.1711

Ribeiro K B, da Silva Zanetti J, Ribeiro-Silva A, et al. (2016) KRAS mutation associated with CD44/CD166 immunoexpression as predictors of worse outcome in metastatic colon cancer. Cancer Biomark; 16: 513-521. Retrieved from https://doi.org/10.3233/CBM-160592

Sadot E, Kraus S, Stein M, et al. (2014) CD24 gene polymorphism--a novel prognostic factor in esophageal cancer. The International journal of biological markers; 29: e49-e54. Retrieved from https://doi.org/10.5301/jbm.5000071

Sheng L and Shui Y. (2011) Clusters of differentiation 24 polymorphism and hepatocellular carcinoma. Hepatology; 54: 2273; author reply 2273-2274. Retrieved from https://doi.org/10.1002/hep.24676

Siegel R L, Miller K D, Goding Sauer A, et al. (2020) Colorectal cancer statistics, 2020. CA Cancer J Clin; 70: 145-164. Retrieved from https://doi.org/10.3322/caac.21601

Soliman A S, Bondy M L, El-Badawy S A, et al. (2001) Contrasting molecular pathology of colorectal carcinoma in Egyptian and Western patients. British journal of cancer; 85: 1037-1046. Retrieved from https://doi.org/10.1054/bjoc.2001.1838

Song M, Hu F B, Spiegelman D, et al. (2015) Adulthood Weight Change and Risk of Colorectal Cancer in the Nurses' Health Study and Health Professionals Follow-up Study. Cancer prevention research; 8: 620-627. Retrieved from https://doi.org/10.1158/1940-6207.CAPR-15-0061

Spelt L, Sasor A, Ansari D, et al. (2018) The Prognostic Role of Cancer Stem Cell Markers for Long-term Outcome After Resection of Colonic Liver Metastases. Anticancer Res; 38: 313-320. Retrieved from https://doi.org/10.21873/anticanres.12224

Stojkovic Lalosevic M, Stankovic S, Stojkovic M, et al. (2017) Can preoperative CEA and CA19-9 serum concentrations suggest metastatic disease in colorectal cancer patients? Hellenic journal of nuclear medicine; 20: 41-45. Retrieved from https://www.researchgate.net/profile/Milica-StojkovicLalosevic/publication/315476362_Can_preoperative_CEA_and_CA19-

9_serum_concentrations_suggest_metastatic_disease_in_colorectal_cancer_ patients/links/5b30bea60f7e9b0df5c742f3/Can-preoperative-CEA-andCA19-9-serum-concentrations-suggest-metastatic-disease-in-colorectalcancer-patients.pdf

Tomašević R, Milosavljević T, Stojanović D, et al. (2016) Predictive Value of Carcinoembryonic and Carbohydrate Antigen 19-9 Related to Some Clinical, Endoscopic and Histological Colorectal Cancer Characteristics. Journal of 


$\begin{array}{llcll}\text { medical biochemistry; } & 35: & 324-332 . & \text { Retrieved } & \text { from } \\ \text { https://doi.org/10.1515/jomb-2016-0014 }\end{array}$

Wang J, Wang X, Yu F, et al. (2015) Combined detection of preoperative serum CEA, cancer patients. International journal of clinical and experimental pathology; 8: 14853-14863.

Wang L, Liu R, Li D, et al. (2012) A hypermorphic SP1-binding CD24 variant associates with risk and progression of multiple sclerosis. American journal of translational research; 4: 347-356. Retrieved from https://www.ncbi.nlm.nih.gov/pmc/articles/PMC3426393/

Yan S, Xu D, Jiang T, et al. (2014) CD24 single nucleotide polymorphisms and cancer risk. Tumor Biology; 35. Retrieved from https://doi.org/10.1007/s13277014-2127-2

Yeo M K, Lee Y M, Seong I O, et al. (2016) Up-regulation of Cytoplasmic CD24 Expression Is Associated with Malignant Transformation but Favorable Prognosis of Colorectal Adenocarcinoma. Anticancer Res; 36: 6593-6598. Retrieved from https://doi.org/10.21873/anticanres.11264

Youssef M R, Attia Z I, El-Baz R A, et al. (2017) Genetic polymorphisms of NFkB194ins/delATTG and NFkBIA-881A/G genes in Egyptian patients with colorectal cancer. Familial cancer; 16: 517-524. Retrieved from https://doi.org/10.1007/s10689-017-9992-y

Youssef M, Ewieda H, Ali A, et al. (2013) Comparison between CEA, CA 19-9 and CA 72-4 in Patients with Colon Cancer. International Journal of Tumor Therapy; 2: 26-34.

Zhang Y, Li B, Zhang X, et al. (2017) CD24 is a genetic modifier for risk and progression of prostate cancer. Mol Carcinog; 56: 641-650. Retrieved from https://doi.org/10.1002/mc.22522 